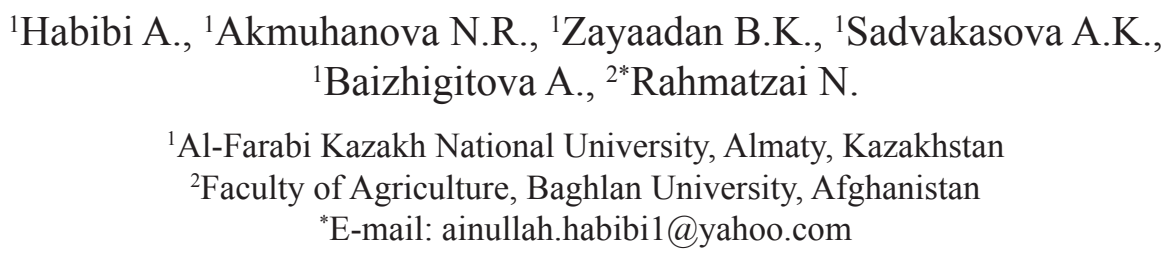

\title{
The soil algal flora as bio-indicators of the soil condition in the Baghlan region (Afghanistan)
}

\begin{abstract}
Soil algae are present in all kinds of soils, both arable and virgin, in large amounts and in great diversity. They are photoautotrophic, aerobic organisms obtain $\mathrm{CO}_{2}$ from atmosphere and energy from sunlight and synthesize their own nutrients. They are unicellular, filamentous and/or colonial. Soil algae are divided into four main phyla like Cyanophyta, Chlorophyta, Xanthophyta, Bacillariophyta. They play a crucial role in soil fertility. Particularly Cyanophycae members are known by their significant role in the nitrogen source of soils. There are numerous works about the soil algal flora as bio-indicators of the soil condition in the world but no research has been carried out on Baghlan region.

This article presents the results of the study on the species diversity of soil algal flora in Baghlan region (Afghanistan). In order to study the soil algal flora in the Baghlan region, soil sample were collected in August, 2016. Collected soil sample were cultured in standard medium and soil algae were observed thoroughly under research microscope and identified with the help of standard literature on algae. According to the results of the study, soil algocenoses in Baghlan province, Chashmaishir and Shamarq characterized by the predominance of cyanobacteria. We have identified 4 divisions, 8 classes, 18 orders, 24 families, 28 genera, 46 species. According to the analysis of certain kinds of saprophytic-indicator, the soil of the Baghlan region characterized as the $\beta$-mesosaproprobic. The saprobity index according to the method of Pantle - Buck was s 2.8. The main representatives of algae indicator in soils are $\alpha$, $\beta$-mesosaprobics of microalgae.
\end{abstract}

Key words: soil aglal flora, soil algocenoses and $\alpha, \beta$ - mesosaproproic.

\section{Introduction}

Algae can be finding in most of the soils where humidity and sunshine are available. Their number in soil commonly ranges from 100 to 10,000 per gram of soil. They are photoautotrophic, aerobic organisms and acquire carbon dioxide from atmosphere and energy from sunlight and synthesize their own food [1].

They are unicellular, filamentous or colonial. Four different phyla of algae are recognized in soil: green (Chlorophyta), blue-green (Cyanobacteria), yellow-green (Xanthophyta), and diatoms or golden-brown algae (Bacillariophyta). Out of these four phyla, blue-green algae and grass-green algae are more abundant in the soil. The green-grass algae and diatoms are dominant in the soils of temperate region while blue-green algae predominate in tropical soils. Green-algae prefer acid soils while blue green algae are commonly found in neutral and alkaline soils. The most common genera of green algae found in soil are: Chlorella, Chlamydomonas, Chlorococcum,
Protosiphon etc. and that of diatoms are Navicula, Pinnularia. Synedra, Frangilaria. Blue green algae are unicellular, photoautotrophic prokaryotes containing Phycocyanin pigment in addition to chlorophyll. They do not posses flagella and do not reproduce sexually. They are common in neutral to alkaline soils. The dominant genera of BGA in soil are: Chrococcus, Phormidium, Anabaena, Aphanocapra, Oscillatoria etc. Some BGA posses specialized cells known as «Heterocyst» which is the sites of nitrogen fixation. BGA fixes nitrogen (non-symbiotically) in puddle paddy/water logged paddy fields (20-30 kg/ha/season). There are certain BGA which possess the character of symbiotic nitrogen fixation in association with other organisms like fungi, mosses, liverworts and aquatic ferns Azolla, eg AnabaenaAzolla association fix nitrogen symbiotically in rice fields [2].

Soil algae are photoautotrophs. These species do not depend on the organic matter (carbon content) of the soil and play a role as primary colonizers. They 
produce large amounts of secreted polysaccharides that promote soil aggregation at the surface and they are capable of nitrogen fixation. Soil habitats are the most important non-aqueous ecosystems for microalgae where these organisms contribute to soil formation and stability In addition, microalgae contribute to energy and matter flux Green and blue green microalgae populations in upper topsoil can perform valuable services for soil ecosystems and agriculture One of the major benefits of microalgae is the generation of organic matter from inorganic substances In addition to providing a food source for other microorganisms, nematodes, and invertebrates, microalgae produce biologically active compounds such as enzymes and ions that can affect other components of soil communities, including plants [3-10].

In conditions of intensification of agriculture and a sharp increase of anthropogenic impact on the environment, particularly the soil cover, algae significantly increases the role of biological factors in extending the fertility of soils and their reclamation. A great help in this condition could be skillful use and development of soil biota, permanent and significant component of which are algae [11].

Soil algae have a various impact on the soil and its fertility, the most important aspect of the latter is the accumulation of organic matter. Filling the space unoccupied by higher plants, algocenoses serve as a factor of additional biomass [12].

Organic matter of algae easily available to many heterotrophic organisms. Therefore, their development stimulates the activity of many soil microorganisms. Assimilating the ash elements from the soil, they participate in small biological circulation of substances, as well as contribute to the preservation of moisture in the soil.

Soil algae absorbing various salts; affect the redistribution of elements in soil. Biological fixation of easily soluble salts can be a great value. Substances absorbed by the algae, or remain available to the roots or quickly return to the cycle of matter after their death. Many species of Cyanobacteria can fix atmospheric nitrogen, which is an additional source of nitrogen nutrition of higher plants.

Cyanobacteria compose active part of the soil microbiota. Due to the physiological and biochemical characteristics of protoplast, microscopic size, autotrophy, ability to fix atmospheric nitrogen and «ephemerality» of vegetation they can survive even in extremely unfavorable of existence conditions. As an explerents for life strategy, having low competitive power and high-energy reproduction, Cyanobacteria can explore space, especially in terrestrial eco- systems, where the limiting factors significantly limit the development of higher plants [13]. In this regard, the study of algal flora experiencing of different types and levels of anthropogenic impacts is extremely important, because it allows to identify the response of organisms to specific contaminants, establishes the degree of adaptation to the action of disturbing factors, determines the possibility of using certain species for assessment of soil condition, identifies the ways of a biological re-cultivation.

The blue green algae increase in soil pores with having filamentous structure and production of adhesive substances, excrete of growth-promoting substances such as hormones (auxin, gibberellin), vitamins, amino acids, increase in water holding capacity through their jelly structure, increase in soil biomass after their death and decomposition, decrease in soil salinity, prevent weeds growth, increase in soil phosphate by excretion of organic acids [14-18].

Cyanobacteria or Blue green algae (BGA) are a group of microorganisms that can fix the atmospheric nitrogen. BGA can adapt to various soil types and environment which has made it cosmopolitan in distribution. Efficient nitrogen fixing strains like Nostoc linkia, Anabaena variabilis, Aulosira fertilisima, Calothrix sp., Tolypothrix sp., and Scytonema sp. were identified from various agro-ecological regions and utilized for rice production [19]. Thus, the aim of this work is to study the species composition, structure of algal flora and anthropogenic-affected soils of Baghlan region.

\section{Materials and methods}

During the study, field collections and laboratory analyses were conducted, using methods generally accepted with algological practice. Algological collection of samples, the study of the taxonomy carried out in Chashmaishir and Shamarq areas of Baghlan province that located at $36^{\circ} 00^{\prime} \mathrm{N}$ latitude and $68^{\circ} 30^{\prime} \mathrm{E}$ longitude, altitude $531 \mathrm{~m}$ above sea level, minimum temperature during the winter $0-20^{\circ} \mathrm{C}$ and maximum temperature during the summer is $47^{\circ} \mathrm{C}$, steppe climate, little rainfall about $282 \mathrm{~mm}$ of precipitation falls annually [20].

The physical and chemical properties of the soil were as follows: $\mathrm{pH} 8.2$, containing of high calcium carbonate 10-12 percent [21], generally lack of nitrogen and phosphorus, soil characteristics alkaline and mineral soils containing 1-2\% organic matter [22].

Algological samples collected in summer August, 2016. 12 mixed soil samples, were collected for analysis by algological classical methods. Determi- 
nation of taxonomic composition of microalgae was carried out in the laboratory of phototrophic microorganisms at the Department of Biotechnology of al-Farabi KazNU. For identification of microalgae definitions from the «Determination of taxonomic composition of blue-green algae of Central Asia» were used $[23,24,25]$.

To identify the species composition of the algae, culture methods were used: soil culture with glass fouling and agar cultures. $\times 50$ field of view was observed on at least three preparations. The number of organisms was assessed by the frequency scale after the transfer to the $\times 100$ field of view. The frequency of occurrences is recorded at 6 point system [26]. Types of microalgae indicators established by the atlas, saprobity index was calculated by the method of Pantle-Buck [27].

\section{Results and their discussion}

In the results of conducted research of the soil of Baghlan province in the area of Chashmaishir and Shamarq 46 species were detected belonging to 4 divisions, 8 classes, 18 forms, 24 families, 28 genera (Fig. 1) of algae and cyanobacteria. Taxonomic structure of algal flora was as follow: Cyanobacteria - 21 species (45\%), Bacillariophyta - 5 species (10\%), Xanthophyta species - 5 (10\%), and Chlorophyta - 15 species (33\%). Dominant position of algae groups occupied by the representatives of Cyanobacteria and Chlorophyta. However, the dominant role belongs to the cyanobacteria, typical representatives of soil ecosystems.

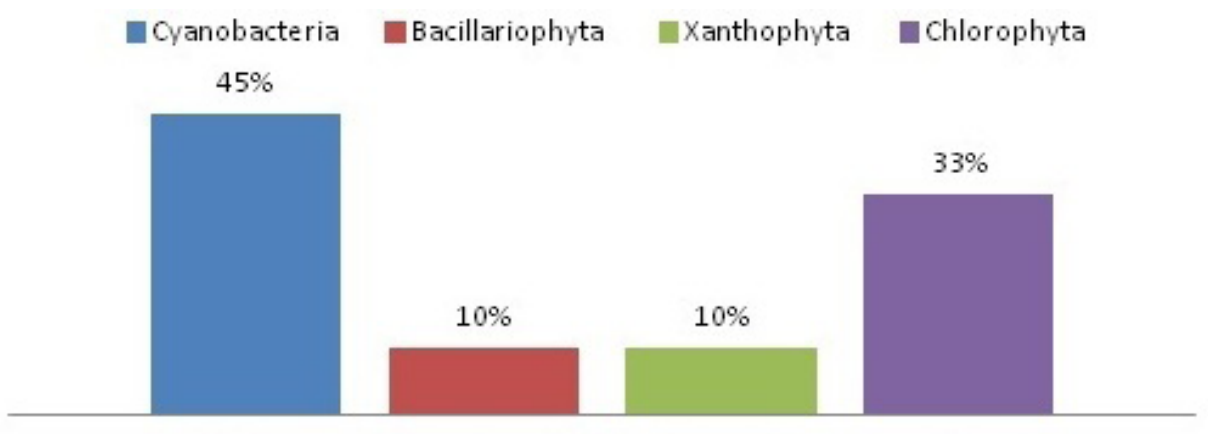

The taxonomic structure of soil algoflora of Baghlan province

Figure 1 - Taxonomic structure of alga flora of Baghlan region

In the selected soils from the Chashmaishir area were revealed 44 species of microalgae and cyanobacteria. Five species are yellow-green, 19 species are cyanobacteria, 5 species are diatom and 14 species are green. Group which has the most frequently occurring types (frequency of $40 \%$ and above) is represented by 6 types: Chlorococcum sp., Phormidium autumnale, Nitzschia palea, Chlorella vulgaris and Nostoc linckia, Anabaena sp. Most of the identified species (50\% from the total species) had a low prevalence (below 10\%), i.e., occurred in no more than 1-3 samples. The complex of dominant species is very rich and included representatives of the divisions of green algae and cyanobacteria (Fig. 2).

In algological samples obtained from soils of the Shamarq area identified 38 species and variations of microalgae and cyanobacteria. 17 species were cyanobacteria, i.e., blue-green -3 , green -12 , diatom -4 . In those sample dominated: from the blue-green - Nostoc verricosum Vauch., Phormidium autumnale Cylindrospermum licheniforme, Nostoc commune.
From the diatom identified: Navicula cohnii, Synedra ulna, Diatoma huemale, Cumbella ventricosa Kuetz. From the yellow-green algae: Botrydiopsis arhiza, Characiopsis anabaenae, Heterococcus caespitosus. From the green dominated - Chlamydomonas debaryana, Chlamydomonas minutissima, Chlorococcum infusionum, Scenedesmus obliquus, Desmococcus livaceus, Chlorella vulgaris Beijerinck, Chlorella ellipsoidea (Fig. 3).

Algae are reliable indicators of the dynamics of pollutants in soil. They can indicate the presence of soil contaminants, quickly changing the soil algal flora. In the result of changes the species composition and abundance of soil algae, formed similar in composition algocenoses that reflects the level of soil contamination. In subsequently years, the range of their use as indicators has grown considerably. Large use of algae found in the study of fertility of soils and effects of chemicals, when determining the extent of urban loads on the soil and, especially for evaluating different types of anthropogenic and industrial 
pollution. Not so long ago, soil algae included in the monitoring associated with the problem of nature protection [28].

In the result of the analysis of certain types of microalgae and cyanobacteria revealed the presence of 10 species of indicator-saprobic species, including alpha-mesosaprobic $(\alpha)-2$, beta-mesosaprobic $(\beta)$ - 3, polymesosaprobic $(p)-2$, alpha-beta - mesosaprobic $(\alpha-\beta)-1$, beta-alpha-mesosaprobic $(\beta-\alpha)-1$, alpha-beta-mesosaprobic ( $\beta$-p)-1 (Table 1).

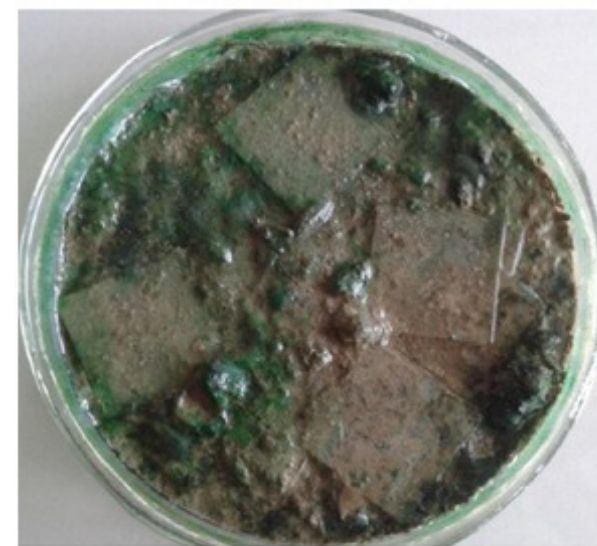

A

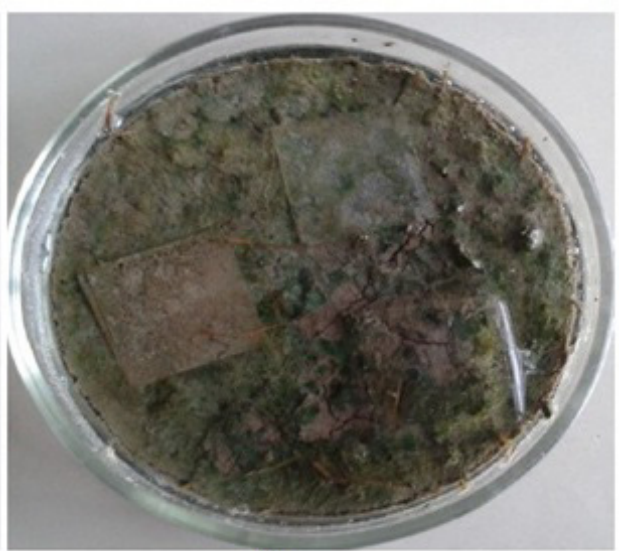

B

Figure 2 - Soil samples from Chashma-i-shir (A) and Shamarq (B)

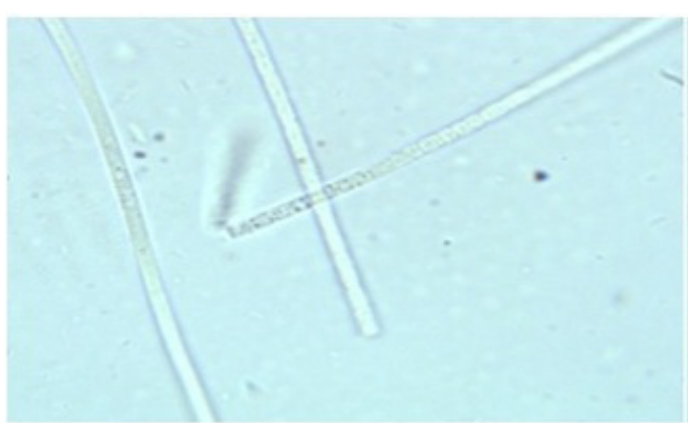

A

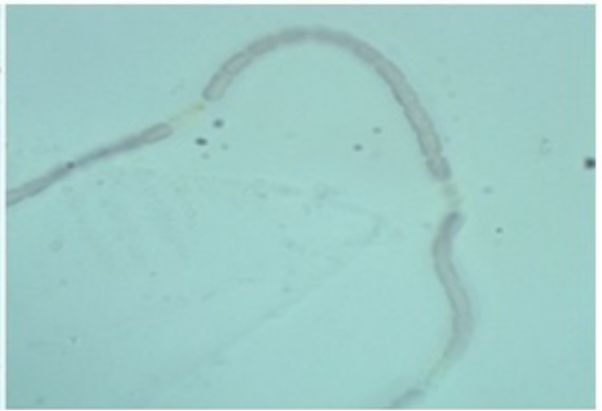

B

Figure 3 - Bacteria cell from Chashmaishir (A) and Shamarq (B) soils

Table 1 - Indicator-saprobic microalgae and cyanobacteria detected in the soils of Baghlan region

\begin{tabular}{|c|c|c|c|c|c|}
\hline № & Species & Saprobity & S & Frequency, $\mathrm{h}$ & Sh \\
\hline 1 & Oscillatoria chlorina & $\mathrm{p}$ & 3.8 & 5 & 19 \\
\hline 2 & Oscillatoria brevis & $\alpha$ & 2.8 & 9 & 25.2 \\
\hline 3 & Pseudanabaena catenata & $\alpha-\mathrm{p}$ & 3.6 & 7 & 25.2 \\
\hline 4 & Phormidium uncinatum & $\beta-\alpha$ & 2.6 & 5 & 13 \\
\hline 5 & Nostoc pruniforme & $\beta$ & 2 & 3 & 6 \\
\hline 6 & Nitzschia palea & $\alpha$ & 2.75 & 5 & 13.75 \\
\hline 7 & Navicula cuspidata & $\alpha-\beta$ & 2.6 & 5 & 13 \\
\hline 8 & Pediastrum boryanum & $\beta$ & 2 & 5 & 10 \\
\hline 9 & Scenedesmus acutus var. quadricauda & $\beta$ & 2 & 7 & 14 \\
\hline 1 & Chlorella vulgaris & $\mathrm{p}$ & 3.6 & 7 & 25.2 \\
\hline
\end{tabular}


So, part of the types of indicator organisms characterizes the studied soil as $\beta$-mesosaprobicarea. The saprobity index according to the method of PantleBuck $\mathrm{S}$ is 2.8 .

From the literature it is known that the taxonomic structure of algocenoses simplified proportionally to the degree of human impact, in this case the changing the percentage of divisions to decrease the proportion of green and yellow-green algae and it has results of the negative impact of anthropogenic load. The high content of cyanobacteria indicates that the soil contained in the long-term «stress» [29].

\section{Conclusion}

The present investigations have revealed that algal flora of the soils of the Baghlan region is characterized by relatively high diversity and there are 46 species, forms and varieties, belonging to 4 divisions, 8 classes, 18 forms, 24 families, 28 genera. From certain species of microalgae and cyanobacteria, the saprobity index according to the method of PantleBuck $\mathrm{S}$ is 2.8 . The soil is characterized as moderately polluted soil.

\section{References}

1. Christopher J. (2015) Soil Microorganisms as Primary Drivers of Essential Ecological Processes. Northern Australia \& land care. http://www.futuredirections.org.au/publication/under-our-feet-soil-microorganisms-as-primary-drivers-of-essential-ecological-processes/

2. http://agriinfo.in/default.aspx?page=topiclist \& superid $=5 \&$ catid $=20$

3. Hastings K.L., Smith L.E., Lindsey M.L. (2014) et al. Effect of microalgae application on soil algal species diversity, cation exchange capacity and organic matter after herbicide treatments [version 1; referees: 1 approved, 1 not approved] F1000Research 3:281 (doi: 10.12688/f1000research.4016.1)

4. Goyal S.K. (1995) Algae and the soil environment. Phykos. 1997; 36: 1-13.

5. Zenova GM, Shtina EA, Dedysh SN, et al.: Ecological relations of algae in biocenoses. Mikrobiologiya. 64(2): 121-133.

6. Metting B. (1981) The systematics and ecology of soil algae. Bot Rev. 47(2): 195-312.

7. Kuzyakhmetov G.G. (1998) Algological evaluation of the toxicity of copper compounds in grey forest soil and leached chernozem. Eurasian Soil Sci. 31(8): 877-882.
8. Starks T.L,. Shubert L.E., Trainor F.R. (1981) Ecology of soil algae: a review. Phycologia.20(1): 65-80.

9. Ruble R.W., Davis J.S. (1988) Soil algae from fallow potato fields in south Florida (USA) marl. Nova Hedwigia. 47(3-4): 403-414.

10. Alexander M. (1977) Introduction to Soil Microbiology. Wiley, NY. 467.

11. Novichkova - Ivanova L. N. (1977) About the role of soil algae and biocenosis // The development and significance of algae in soil non-Black earth zone: Materials of interuniversity conference. -Perm. - P. 62-64

12. Shtina Y. A. (1990) Soil algae as an ecological indicators //Botanical magazine. - ed.75. - № 4. - P. 441-453

13. Domracheva L. I. (2006) Algo-mycological complexes in soils upon their chemical pollution / L.I. Domracheva, Y.V. Dabakh, L.V. Kondakova, A.I. Varaksina // Eurasian Soil Science, - v. 39. 591-597

14. D. Sahu, I. Priyadarshani, B. Rath. (2012) Cyanobacteria - as potential biofertilizer: CIBTech Journal of Microbiology. Vol. 1 (2-3). P. 20-26..

15. Roger PA, Reynaud PA (1982). Free-living Blue-green Algae in Tropical Soils. Martinus Nijh off Publisher, La Hague.

16. Rodriguez AA, Stella AA, Storni MM, Zulpa G, Zaccaro MC (2006) Effects of cyanobacterial extracelular products and gibberellic acid on salinity tolerance in Oryza sativa L. Saline System, 2: 7.

17. Saadatnia and Riahi (2009) Cyanobacteria from paddy fields in Iran as a biofertilizer in rice plants, Plant Soil and Environment 55(5) 207-212.

18. Wilson LT (2006). Cyanobacteria: A Potential Nitrogen Source in Rice Fields. Texas Rice 6 9-10.

19. Prasad R C and Prasad B N (2001) Cyanobacteria as a source Biofertilizer for sustainable agriculture in Nepal. Journal in Plant Science Botanica Orientalis $127-133$.

20. http://en.climate-data.org/location/31392/. Retrieved 9 September 2016.

21. Salem, M.Z. and Hole, E.D. (1969), Soil Geography and Factors of Soil Formation in Afghanistan. Soil Science, Vol. 107, No.4.

22. UNDP/FAO T.A. Report No. 3016 - (1971), Soil fertility and fertilizer use in Afghanistan (based on work of Dr. Tamboli, FAO expert). FAO, Rome.

23. Kuzyakhmetov G. G., Dubovik I. Y. (2001) Methods of studying soil algae: the manual, Ufa, $56 \mathrm{p}$. 
24. Shtina Y. A. (1951) Methods of studying soil algae / Y. A. Shtina // coll. of articles «Microorganisms as a component biocenosis» M.: Science, 1984. P. 58-74.

25. Determinant of freshwater algae USSR / Executive editor M.M. Gollerbach. - L: Science, ed. 1-14.

26. Muzafarov A.M., Yergashev A.Y., Khalilova S.Kh. (1988) Determinant of blue-green algae in
Central Asia. -Tashkent: Fan, - ed.2. - p. 406-815.

27. Bachura Yu. M., (2011) Using of methods of soil and agar cultures in the study of soil algae / M.Yu. Bachura, O.M. Khramchenkova // Gomel State University. - № 4. - P.107-113.

28. Kabirov R.R. (1995) Algotesting and algoindication -Ufa: BGPI, $-125 \mathrm{p}$.

29. Los D. A. (2007) How cyanobacteria feels stress? Chemistry and Life. № 7.33 p. 